\title{
Collapsing towards Extinction? Trade in Birds Carcasses for Traditional Medicine and the Decline of Vulture Population in Katsina State, Nigeria
}

\author{
${ }^{1 *}$ MUHAMMAD, ND; ${ }^{2}$ MUSTAPHA, ZK \\ ${ }^{\prime}$ Department of Geography, Bayero University Kano, Nigeria \\ ${ }^{2}$ Department of Environmental Management, Bayero University, Kano, Nigeria \\ *Corresponding Author Email: mndanjuma.geog@buk.edu.ng
}

\begin{abstract}
Decline in vulture populations have seriously reported in Nigeria as in other habits around the world. Human pressure from poisoning, hunting and trading for traditional medicine are key factors leading to decline of vulture population in northern Nigeria. This study examines vulture trading for traditional medicine as risk factor for the raptors population decline in Katsina with a view to providing baseline information for reviewing conservation policies in the State and Nigeria at large. The study is a survey research involving questionnaire administration and interview of seventy two stakeholders who were sampled using snowball sampling technique as follows: vulture stall owners $(\mathrm{n}=58)$ and abattoir employees $(\mathrm{n}=10)$ and traditional healers $(\mathrm{n}=4)$. A total of five locations were surveyed based on the understanding that they possess the most specialized fetish markets and important centres of vulture trading in Katsina State. Percentage and mean were used for data analysis. The study found that trading of vulture is proliferating in the area as more than $50 \%$ of the stalls were opened between 2016 and 2019. It also revealed that $80 \%$ of the fetish stalls are located outside Katsina town for fear of authorities fighting illicit trade of vulture. Also revealed was that prices of vulture vary in space and depend on relationships with customers: a whole vulture costs N21000 (ca. \$55.55) which soars as high as $\mathrm{N} 27000$ (ca. \$75) outside Katsina town and N30000 (ca. \$83) in times of scarcity. This study recommended that there is the need to carry out nationwide comprehensive assessment of trade in avifauna for improving conservation policies and practices in Nigeria.
\end{abstract}

\section{DOI: $\underline{\text { https://dx.doi.org/10.4314/jasem.v24i4.5 }}$}

Copyright: Copyright (C) 2020 Muhammad and Mustapha. This is an open access article distributed under the Creative Commons Attribution License (CCL), which permits unrestricted use, distribution, and reproduction in any medium, provided the original work is properly cited.

Dates: Received: 11 February 2020; Revised: 14 March 2020; Accepted: 22 March 2020

Keywords: carcasses, fetish stalls, traditional medicine, conservation

Biodiversity contributes significantly to human welfare through provision of consumable goods, and the supply of a wide range of services including cultural heritage, environment cleaning and much more (Davies, 2017).The diversity and abundance of life in a country greatly influences the functioning of its ecosystems and the services they provide and therefore a determinant of its natural capital. Nigeria is endowed with a great variety of ecosystems and a number of unique species that serve as a major source of wealth and economic empowerment (Federal Government of Nigeria, 2015). Currently, these rich endowments are facing massive declines worldwide and in Nigeria in particular due to anthropogenic activities, the decrease of decomposition rate of carcasses and with the increase of populations of opportunistic scavengers like canids and rodents at carcasses and dumpsites (Thiollay, 2006; Ogada, 2012; Henriques et al., 2018). Vulture is an important ecosystem species because of their unique services of eating carrion thereby helping to prevent the spread of disease (Hassan and Ismail, 2017). The species has also been behind the success of many African predators such as lions and hyenas by enhancing their ability in locating food resources (Houston, 1974).
They also help promote the flow of energy through food webs by scavenging carcasses (Wilson and Wolkovich, 2011). Aside its role of enhancing the environment, some believed that vulture cure a range of physical and mental illnesses, improve success in gambling and business ventures or increase intelligence in children vulture body parts there for have long been valued (McKean et al., 2013; Saidu and Buij, 2013). In South and West Africa, vulture has been traded for traditional medicine. In Nigeria, seven species of vulture were found which have been significantly affected by trading. The Egyptian vultures (Neophron oercnopterus) which was previously found around northern states of Borno, Jigawa, Zamfara, Katsina Sokoto and Kebbi where it is called Ungulun Masar or Farar Ungulu in local Hausa language (APLORI, 2019) has been slumping to extinction owing to threats including poisoning, habitat loss and trapping for food and witchcraft (Nikolaus, 2001; Keesing et al., 2012). The surging illegal markets for animal parts are increasing pressure on a number of already beleaguered species (Thiollay, 2007). Arguably, vulture killing and trading for traditional medicine and the proliferation of trading of the species reported in West Africa and Nigeria in 
particular (Saidu and Buij, 2013; Henriques et al., 2018) is behind the collapse of its population. As indicated in a national status survey in Nigeria the large scale utilization of vulture for traditional medicine is responsible for decline in vulture population in Nigeria (Ibrahim et al., 2010; Akagu and Adeleke, 2012). This highlights the critical threats that the species continue to face since the $20^{\text {th }}$ century (Nikolaus, 2001).

In northern Nigeria, the trade of vulture is commonly carried out by dealers commonly known as YanShinfida (in the dominant Hausa language) who usually by displaying such items openly in stalls or on mats (Ibrahim et al., 2010). The continued human pressure from trading for traditional medicine and poaching is putting pressure on the population of vulture (IUCN, 2013). Although trading of vulture parts alone poorly explained its population decline, the high explanatory power and the reported sensitivity of raptors to human pressure indicates that the phenomenon can actually cause large-scale disappearance of the species (Carrete et al., 2007; Williams et al., 2014; Morelli et al., 2015).

There has been plethora of studies on vulture in Nigeria e.g Nikolaus, (2001), Thiollay, (2006), Akagu and Adeleke (2012) and Saidu and Buij (2013). With the exception of the aforementioned that published accounts of vulture sold for traditional medicine in markets throughout Nigeria, evidence suggests that the focus of most works is on status, population, habitat as well as nesting through occasional sightings and opportunistic observations. In response to the growing trade in vulture and its potential threat to its population in Nigeria as well as anecdotal statements portraying hike in trading of the species for traditional medicine, this study surveyed fetish stalls with a view to providing insights into how vulture is sold and whether the activities directly or indirectly cause decline in number and diversity of the species in the area. This aspect has been particularly underresearched in Katsina but is crucial for effective design and implement of robust conservation interventions for vulture and raptors in the area and Nigeria in general for their vital ecosystem services.

\section{METHODS AND METHODS}

Study Area: Katsina is located approx.260 kilometers east of the city of Sokoto, 135kilometers northwest of Kano and 80.6 kilometers south east of Maradi in Niger Republic (Danjuma, 2011). It is located between latitude $12^{\circ} 59^{\prime} \mathrm{N}$ and $12^{\circ} 98^{\prime} \mathrm{N}$ and longitude $7^{\circ} 37^{\prime} \mathrm{E}$ and $7^{\circ} 61^{\prime} \mathrm{E}$. All the study locations are located within $30 \mathrm{~km}^{2}$ radius of Katsina town and about $50 \mathrm{~km}^{2}$ to the border of Nigeria with Niger Republic (Figure 1).

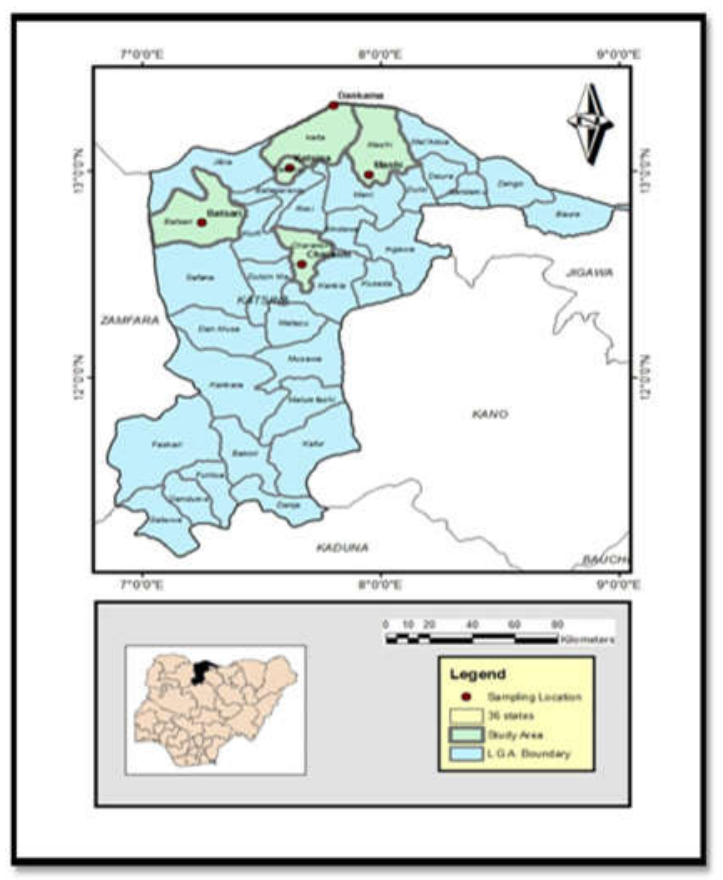

Fig 1: Map Katsina, northwestern Nigeria showing the study locations

The climate of Katsina is the tropical continental type. It is described as 'Aw' by Koppen with distinctive wet and dry seasons caused by the fluctuations of the ITCZ (Inter Tropical Convergence Zone) .The ITCZ separates humid maritime air mass originating from the Atlantic Ocean and dry desert air mass (Danjuma, 2017). Temperature is generally cool in the morning, hot in the afternoon, and very cool in the evening. Maximum temperature range in Katsina is between $29^{\circ} \mathrm{C}$ and $38^{\circ} \mathrm{C}$ but harmattan season (November to February) lowers temperature to about $18^{\circ} \mathrm{C}$ and $27^{\circ} \mathrm{C}$ in the noon. The study area is the Sudan savanna where the indigenous trees grow spontaneously and protected on farms by private access regime (Danjuma, 2017). Some example of notable trees found include Parkia biglobosa, Adansonia digitata, Khaya senegalensis, Fadherbia albida, Tamarindus indica, and Borassus aethiopum, Azadirachta indica, and Eucalyptus camaldulensis. These trees have been supporting wildlife in the area including camel, birds and few borrowing species often found in formally protected areas. Vulture has been one of these species found both in the formal and informal protection areas in the state, however, man plays great role in modifying biodiversity in the Katsina.

This study is a survey research involving questionnaire administration and interview of seventy two stakeholders as follows: vulture stall owners $n=58$ and abattoir employees $\mathrm{n}=10$ (sampled using snowball sampling technique) and traditional healers $n=4$ 
(sampled using purposive sampling). The survey covered twenty eight fetish markets located within 30 metres Katsina because we cannot conduct a state wide survey and based on the understanding that trading of vulture is highest within this area. Inventory of fetish stalls was done with the help of local guides in all the areas visited. Questionnaire was employed to elicit information on vulture trading from fifty eight owners/traders of fetish stalls. In-depth interview was also conducted with ten abattoir workers and four traditional healers. The quantitative data was analyzed using percentage and mean while qualitative data was coded, sorted for reoccurring issues.

\section{RESULT AND DISCUSSION}

Results of the study and issues addressed were outlined and discussed below.

Inventoried Fetish Stalls: Fetish markets are important to the culture of Nigerians because people still prefer to solve their health problems through traditional medicine. This study found that the fetish markets around Katsina were unequally distributed among the villages. There is high concentration of fetish stalls in Charanci and Mashi villages and outside Katsina city (Figure 2). These are villages with rural markets where the species is displayed in the open for sale. The high concentration of fetish stalls found in the villages is due to patronage of vulture or parts by diverse people most of which come from Nigeria and Niger Republic to obtain the products from various traditional healing processes. Additionally, the absence of uncoordinated regulations to stop this category of traders in Katsina State is another important ingredient for the high number of fetish stalls in villages.

This has been supported by Shepherd (2006) who reported that virtually all towns and cities in Indonesia have bird markets and very little is done to regulate or monitor the trade and to ensure it is both legal and sustainable. In many areas of the world, there is the concentration of fetish stalls in villages with rural markets because of fear of regulations banning trade in wildlife which are enforced more in the cities. Buij et al. (2015) found that in 2008 there are about 960 fetish stands in Nigeria which is the highest among the other West African countries (Benin, Mali and Burkina Faso) surveyed.

Growth of Fetish Stalls: Fetish stalls provide materials including parts of birds, mammals, reptiles and raptors for making amulets or talisman for spiritual or magical healing. These are sites revered by local communities for spiritual attributes hence their number has been increasing since 2000. This work found that between 2011 and 2019 there has been astronomical surge in the number of fetish stalls in the markets visited. In four years alone (2016-2019), there were fresh 16 fetish stalls in the area (Table 1). This was attributed to the rising demand of the centres due to surge in spiritual and degenerative ailments such as diabetes, cancer and psychiatric disorders.

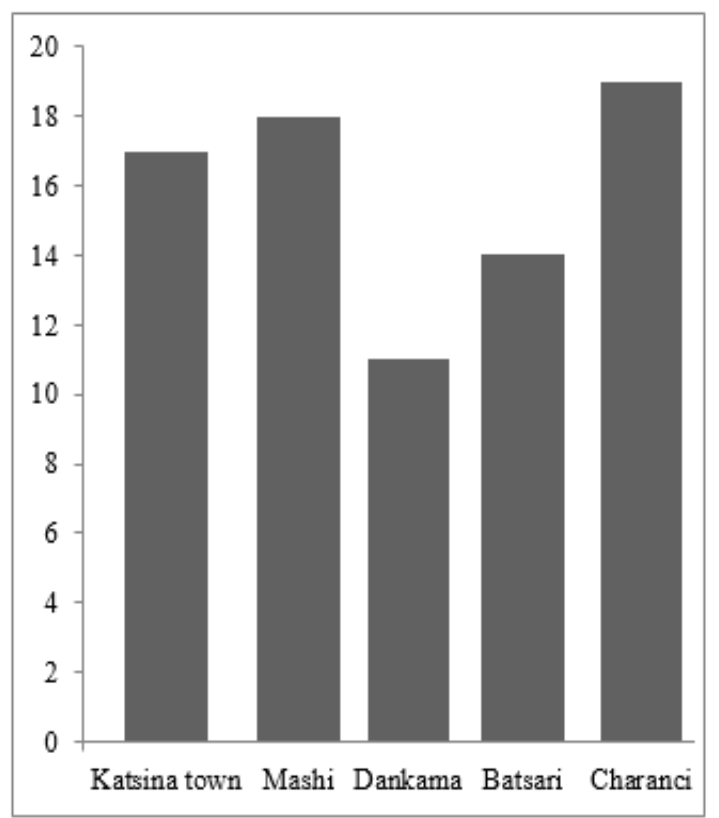

Fig 2: Distribution of Fetish Stalls in the Study Area

Although variation occur in terms of the distribution of the fetish stalls among the study locations, most participants attributed the increase in their number to high patronage from the politicians who visited traditional healers for success in elections. This might be assertions but many studies (Adeola 1992), on fetish markets and activities have reported similar views. Vulture body parts have long been valued in many African cultures, especially in South and West Africa, where some believe that they cure a range of physical and mental illnesses, improve success in gambling and business ventures, or increase intelligence in children (McKean et al. 2013). This study is supported by Saidu and Buij (2013) who revealed that vulture markets are growing in number in northern Nigeria.

They revealed that out of 113 predominantly Hausa medicinal traders in 39 markets within eight states in northern Nigeria, many were encountered in 6 fetish markets in Katsina State. The growth of birds market is not only reported in West Africa. For instance, a survey of three bird markets in Medan (Jalan Bintang, Petisah and Sembahe) in Indonesia revealed that the markets houses more than 50 individual stalls selling birds between 1997 and 2001 (Shepherd, 2006). 
Table 1: Number of Fetish Stalls

\begin{tabular}{llllllll}
\hline SN & Location & \multicolumn{5}{c}{ Period } & $\begin{array}{l}\text { No. of } \\
\text { Fetish Stalls }\end{array}$ \\
\cline { 1 - 1 } & & before & $\mathbf{2 0 0 0 -}$ & $\mathbf{2 0 0 6 -}$ & $\mathbf{2 0 1 1 -}$ & $\mathbf{2 0 1 6 -}$ & \\
1 & & $\mathbf{2 0 0 0}$ & $\mathbf{2 0 0 5}$ & $\mathbf{2 0 1 0}$ & $\mathbf{2 0 1 5}$ & $\mathbf{2 0 1 9}$ & \\
2 & Katsina town & 5 & 4 & 3 & 3 & 2 & 17 \\
3 & Mashi & 2 & 3 & 4 & 4 & 5 & 18 \\
4 & Dankama & 0 & 2 & 3 & 1 & 5 & 11 \\
5 & Batsari & 2 & 2 & 3 & 5 & 2 & 14 \\
& Charanci & 3 & 3 & 2 & 4 & 7 & 19 \\
& No. of stalls & 12 & 14 & 15 & 17 & 21 & 79 \\
& \% & 15.19 & 17.72 & 18.99 & 21.52 & 26.58 & 100.00 \\
\hline
\end{tabular}

\begin{tabular}{lllll}
\multicolumn{4}{c}{ Table 2: Mean Price of vulture } \\
\hline SN & Location & \multicolumn{3}{c}{ Prices of Vulture (N) } \\
\cline { 3 - 5 } & & Whole carcass & Head & Wing \\
\hline 1 & Katsina town & 19000 & 6000 & 3500 \\
2 & Mashi & 20000 & 7500 & 3500 \\
3 & Batsari & 22000 & 7500 & 3000 \\
4 & Charanci & 27000 & 8000 & 3500 \\
5 & Dankama & 21000 & 7000 & 3000 \\
Mean & & $\mathbf{2 1 8 0 0}$ & $\mathbf{7 2 0 0}$ & $\mathbf{3 3 0 0}$ \\
\hline
\end{tabular}

\begin{tabular}{lllll}
\multicolumn{5}{c}{ Table 3: Monthly Sale of Vulture } \\
\hline \multirow{2}{*}{ SN } & Location & \multicolumn{2}{c}{ No. of Vulture or parts sold/month } \\
\cline { 3 - 5 } & & Whole body & Head & Wings \\
\hline 1 & Katsina town & 8 & 6 & 3 \\
2 & Mashi & 2 & 2 & 0 \\
3 & Batsari & 4 & 4 & 0 \\
4 & Charanci & 3 & 7 & 0 \\
5 & Dankama & 14 & 4 & 2 \\
6 & Total & 31 & 23 & 5 \\
& Mean & 6 & 4 & 1 \\
\hline
\end{tabular}

\begin{tabular}{llll}
\multicolumn{3}{c}{ Table 4: Locations where Vulture Carcass are Supplied } \\
\hline SN & Sources & $\begin{array}{l}\text { No. of } \\
\text { Respondents }\end{array}$ \\
\hline & & 12 & \% \\
\hline 1 & Niger Republic & 36 & 45.19 \\
2 & Bauchi (Yankari Game Reserve) & 21 & 26.58 \\
3 & Taraba State & 10 & 12.66 \\
4 & Southern Nigeria & $\mathbf{7 9}$ & $\mathbf{1 0 0 . 0 0}$ \\
\hline
\end{tabular}

Market Price of Vulture/Parts: Vulture trading is a lucrative business in the State as in various parts of Africa. This study revealed that highest and lowest price of whole vulture carcass is recorded in Charanci and Katsina town respectively. The price though high but people can still bear the burden for such highlyvalued species for traditional medicine purposes. The study found that the prices of vulture are not fixed but vary in space and depend on relationships with customers: a whole vulture costs $\mathrm{N} 21000$ (ca. \$55.55) which soars as high as $\$ 27000$ (ca. \$75) outside Katsina town and $\$ 30000$ (ca. \$83) in times of scarcity. Such high prices of vulture are recorded generally in West Africa e.g because of increasing scarcity of the species and rapid disappearance of them from areas where they were formerly common. In the case of Katsina vultures are found most around informally protected areas usually abattoirs but modernization of such facilities have contributed in habitat loss.
A survey by the Nigeria Conservation Fund in 2017 revealed that Kano, Ibadan and Ikare are the hubs of vulture sales where a head could sell for up to $\mathrm{N} 15,000$ and whole body could cost as high as N30,000. This study also found that prices for vulture carcasses or parts are going up. This is a concern for conservation of the species. This finding is in line with Saidu and Buij (2013) as well as Nikolaus (2001) who reported a price of 10,000 (USD 64) by one trader and USD 1020 for large vultures in Nigeria in 1999. Worryingly, vulture prices go up to USD 100 per vulture in western Africa in 2011 (Nikolaus, 2011). Rising prices may stimulate Nigerian traders and hunters to source vultures from neighbouring countries, as already reported by Nikolaus (2001) and confirmed by Saidu and Buij (2013).

Volume of Trade per Location: Vulture trading is done in specialized fetish markets where the entire carcasses or other body parts such as heads and wings are displayed at market stands. This study found that 
whole vulture body is sold more than any other part in the area. The highest and lowest sale of whole vulture body is recorded in Dankama and Mashi respectively (Table 3).

Findings of this study revealed that the whole carcass and heads are more patronized that the wings because based on the average monthly sale (Table 4). The head and wings are mostly sold in Charanci and Katsina town fetish stalls probably because they can be smuggled to markets easily without fear of authorities who reportedly frown at illegal wildlife trading in the area. This study corroborates Saidu and Buij (2013) who reported that trade in vulture parts is widely practised in northern Nigeria, where $93 \%$ of traditional medicine dealers they interviewed had vultures, or their parts, on offer, with $15 \%$ of traders selling vulture heads or complete carcasses.

Sources of Vulture Carcass: Vulture has loss their strongholds around Katsina hence are sourced from far areas for trading. Although few respondents have indicated that vulture are sourced from nearby villages in Niger Republic most reported that the carcasses are transported from far distances for trading in markets around Katsina (Table 4).

Plethora of studies have indicated that carcass of raptors in particular vulture is sourced from distant areas to commercial areas for trading. This study corroborates Saidu and Buij (2013) who reported that vulture carcass is supplied to northern Nigeria from various countries of West Africa including Niger Republic. NCF (2017) reported that vulture carcasses are supplied to the north from as far as Ibadan and the southwest.

Local Perceptions on Risks to Frequently Traded Vulture: One major threat to vulture is trade for traditional medicine. We argued that over the last two decades, vulture population has declined tremendously in Katsina with many species becoming locally extinct while others abandoned traditional range areas. "According to traditional healers vulture trading for traditional medicine has persisted over the last ten years owing to the proliferation of fetish stalls. More vulture carcasses trafficked in markets around the State, so why will they stop?, its lucrative and better than any primary occupation we know."

Given the high number of vulture traded for traditional medicine in West Africa ca. 144,000 (Ogada and Buij, 2001) and that this study supports an earlier assertion by Nikolaus (2011) that the trade probably contributed to increased mortality rates and significant population declines. "According to the abattoir operators, vulture had declined drastically since the year 2005 when the slaughter houses were reconstructed to a closed-system. The only last surviving species are white-backed (Gyps africanus) and Egyptian vulture (Neophron oercnopterus) which are observed around abattoirs and slaughter areas around Katsina." The assertion above supports Gangoso et al. (2013) who indicated that the modernization of livestock management and improved sanitation at slaughterhouses have impacted mainly on Hooded and Egyptian Vultures in many parts of West Africa. Also $98 \%$ of large vultures outside protected areas in central West Africa have declined during 1961-2004 (Thiollay, 2006) and this corroborate the assertions of the participants.

Conclusion: Vulture trading is proliferating at an alarming rate in Katsina as today multiple of fetish stalls have been opened since 2015 despite their threats to the species. Due to spike in the price of vulture carcass in the area owing to high demand for traditional medicine, the bird is ultimately going to extinction and many of its over used species might never even show up. This study recommended that there is the need to carry out comprehensive assessment of trade in avifauna for improving conservation policies and practices in Nigeria. There is the need also to sensitize the public on the importance of conservation of vulture in order to scale down the rate at which the species and its parts are over harvested in the study area and Nigeria at large.

\section{REFERENCES}

Akingboye, O (2017). Nigeria Vultures Face Extinction. The Guardian, 7/8/2017

A.P. Leventis ornithological Research Institute, APLORI (2019). The Egyptian Vulture Project, Jos, Nigeria

Akagu, R; Adeleke, A (2012). Current status and threats facing the Nigeria vultures. Submitted to the pan-African Vulture Summit, Masai Mara, Kenya 16-20 April 2012. Nigerian Conservation Foundation

Buij, R; Croes, BM; Gort, G; Komdeur, J (2013). The role of breeding range, diet, mobility and body size in associations of raptor communities and land-use in a West African savanna. Biol Conserv., 166: 231-246.

Buij, R; Nikolaus, G; Whytock, R; Ingram, DJ; Ogada, D (2015). Trade of threatened vultures and other raptors for fetish and bushmeat in West and Central Africa. Oryx, 1:11 
Carrete, M.; Grande, J. M.; Tella, J. L.; SanchezZapata, J.A.; Donaza, J.A.; Diaz-Delgado, R.; Romo, A. (2007). Habitat, human pressure, and social behavior: Partialling out factors affecting large-scale territory extinction in an endangered vulture. Biological Conservation, 136: 143-154

Davies, J (2017). Biodiversity and the Great Green Wall: managing nature for sustainable development in the Sahel. Ouagadougou, Burkina Faso: IUCN

Federal Government of Nigeria (2015). Fifth National Biodiversity Report. Nigeria

Gangoso, L; Agudo, R; Anado'n, JD; et al. (2013). Reinventing mutualism between humans and wild fauna: insights from vultures as ecosystem services providers. Conserve. Let. 6, 172-179.

Henriques, M; Granadeiro, JP; Monteiro, H; Nuno, A; Lecoq, M; Cardoso, P et al. (2018). Not in wilderness: African vulture strongholds remain in areas with high human density. PLOS ONE, 13(1): e0190594.

Houston, DC (1974). Food searching behaviour in Griffon Vultures. African Journal of Ecology 12: 63-77.

Ibrahim, JA; Muazzam, I; Jegede, IA; Kunle, OF (2010). Medicinal plants and animals sold by the "Yan-Shimfidas" of Sabo Wuse in Niger State, Nigeria. African Journal of Pharmacy and Pharmacology, 4: 386-394.

IUCN (2013). Vultures - the silent victims of Africa's wildlife poaching. http://www.iucn.org/?13529/Vulturessilentvictims- of-Africas-wildlife-poaching (visited October 9, 2014).

Hassan, TA; Ismail, OA (2017). Identification of vulture species around galagu station in Dinder national park. Biodiversity Int J., 1(6):72-75.

Ogada, DL; Keesing, F (2010). Decline of raptors over a three-year period in Laikipia, central Kenya. Journal of Raptor Research, 44: 129-135.

Ogada, DL; Torchin, ME; Kinnaird, MF; Ezenwa, VO (2012). Effects of vulture declines on facultative scavengers and potential implications for mammalian disease transmission. Conserv Biology, 26: 453-460.
McKean, S; Mander, M; Diederichs, N et al. (2013). The impact of traditional use on vultures in South Africa. Vulture News, 65:15-36.

Morelli, F; Kubicka, AM; Tryjanowski, P; Nelson, E (2015). The vulture in the sky and the hominin on the land: three million years of human vulture interaction. Anthrozoos, 28: 449-468.

Nikolaus, G (2001). Bird exploitation for traditional medicine in Nigeria. Malimbus 23: 45-55.

Nikolaus, G (2011). The fetish culture in West Africa: An ancient tradition as a threat to endangered birdlife? In: Tropical vertebrates in a changing world. Schuchmann, K-L (Ed.). Bonner Zoologische Monographien, Zoologisches Forschungsmuseum Alexander Koenig, Bonn.

Ogada, DL; Buij, R (2011). Decline of the Hooded Vulture Necrosyrtes monachus across its African range. Ostrich, 82:101-113.

Saidu, Y; Buij, R (2013). Traditional medicine trade in vulture parts in northern Nigeria. Vulture News, $65,4: 14$

Shepherd, CR (2006). The bird trade in Medan, north Sumatra: an overview. BirdingASIA, 5: 16-24

Söderström, B; Kiema, S; Reid, RS (2003). Intensified agricultural land use and bird conservation in Burkina Faso. Agric Ecosyst Environ. 99: 113124.

Thiollay, J-M (2006). Severe decline of large birds in the Northern Sahel of West Africa: a long-term assessment. Bird Conserv. Int., 16: 353-365.

Thiollay, J-M (2007). Raptor population decline in West Africa. Ostrich, 78: 405-413.

Williams, VL; Cunningham, AB; Kemp, AC; Bruyns, RK (2014). Risks to birds traded for African traditional medicine: a quantitative assessment. PLoS ONE, 9: 1-17.

Taylor, ME; Fox, J (1992). The fetish market, Lome', Togo. The Nigerian Field, 57: 119-125.

Wilson, EE; Wolkovich, EM (2011). Scavenging: how carnivores and carrion structure communities. Trends Ecology Evolution, 26: 129-135. 